\title{
Male crossing over and genetic sexing systems in the Australian sheep blowfly Lucilia cuprina
}

\author{
GEOFFREY G. FOSTER, GAYE L. WELLER \& GEOFFREY M. CLARKE \\ CSIRO Division of Entomology, GPO Box 1700, Canberra ACT 2601, Austratia
}

\begin{abstract}
Field-female killing (FK) systems based on deleterious mutations and Y-autosome translocations are being evaluated for genetic control of the Australian sheep blowfly, Lucilia cuprina. Experience during field trials has shown that mass-reared colonies of FK strains are subject to genetic deterioration, caused mainly by genetic recombination in males. A previous study found higher male recombination frequencies in two Y-linked translocation strains than in chromosomally normal males. However, the results of the present study indicate that breakage of the $Y$ chromosome is neither sufficient nor necessary for increased levels of male recombination. The frequency of male recombination appears to be unrelated to the presence of specific chromosome rearrangements.
\end{abstract}

Keywords: genetic control, genetic sexing, Lucilia cuprina, male recombination.

\section{Introduction}

Genetic sexing systems facilitate separation or killing of mass-reared insects according to sex. This is most frequently accomplished by artificially linking appropriate mutations with sex using rearrangements between sex-determining chromosomes and other chromosomes, although other sex-determining mechanisms can be exploited (reviewed by Whitten \& Foster, 1975). Insects with Y-mediated sex determination, such as most higher Diptera (Boyes, 1967; Ullerich, 1963) are especially amenable to genetic sexing. Genetic sexing may assist in rearing economically important insects such as silkworms (Tazima, 1964), or in genetic pest control strategies involving release of sterilized or genetically altered males.

In Australia a genetic sexing system which operates in the field is central to proposed large-scale control programmes against the blowfly Lucilia cuprina, a major myiasis pest of the Australian sheep industry (Foster, 1989; Foster et al., 1985, 1988; Whitten, 1979; Whitten et al., 1977). This field-female killing (FK) system combines recessive conditional-lethal mutations with a translocation involving the $\mathrm{Y}$ chromosome and two autosomes.

Correspondence: Dr G. G. Foster, CSIRO Division of Entomology, GPO Box 1700, Canberra ACT 2601, Australia.
FK-strain females are homozygous for one or more eye-pigment mutations and have white eyes. They can survive in cages, but they are functionally blind, rarely surviving long in the field; in other words the eyecolour mutations are recessive lethals under field conditions (Whitten et al., 1977).

FK-strain males carry the eye-colour mutations on a single set of normal autosomes, and the wild-type alleles on the translocation. They have normal eye pigmentation and vision, and are competitive in the field, transmitting the translocation to their sons and the mutations to their daughters.

When the daughter of a released FK male, heterozygous for the mutations, is mated by a released male, a proportion (half or more, depending on the number of mutations) of her daughters is homozygous and thus unable to survive to reproductive maturity (Whitten et al., 1977; see fig. 1 of Foster et al., 1985 or 1988).

Matings of wild females by released FK-strain males lead to reduced population fertility from the semisterility of the translocation and, with sustained releases, a high frequency of homozygosis for the mutations in non-translocation zygotes of field origin (Foster et al., 1985, 1988; Whitten, 1979; Whitten et al., 1977). Semisterility and homozygosis combine to give genetic death rates approaching 94 per cent with presently available FK strains of $L$. cuprina. This system has successfully suppressed sheep blowtly 
populations in two field trials conducted in 1984-86 (R. J. Mahon, T. L. Woodburn and G. G. Foster, unpublished observations).

For long-term pest suppression campaigns FK systems are likely to be more cost-effective than the sterile-insect technique (SIT), since at low release rates FK males can cause higher genetic death rates in density-influenced populations than sterile males (Foster et al, 1988).

Genetic sexing requires tight linkage of particular autosomal mutations to sex. In most higher Diptera, the frequency of crossing over in males is usually several orders of magnitude lower than in females (Foster et al., 1980a; Milani, 1975; Rössler, 1982a; Rössler \& Rosenthal, 1990). It has been tacitly assumed that in this group of insects, the difference in crossover frequency between the sexes would give sufficiently tight linkage in genetic sexing systems using Y-linked translocations (Foster et al., 1978; McDonald, 1971; Robinson \& Van Heemert, 1982; Wagoner et al., 1974; Whitten, 1969, 1979; Whitten et al., 1977; Whitten \& Foster, 1975).

However, genetic sexing systems are vulnerable to low levels of male recombination. Such recombination may separate one or more of the mutations from the male-determining region of the $\mathrm{Y}$ chromosome. If the products of such recombination enjoy a selective advantage in rearing colonies, linkage of the critical mutation to sex can rapidly disappear (Busch-Petersen, 1989; Foster et al., 1980a; Hooper et al, 1987; Saul,
1984). In field trials this has contributed to serious genetic deterioration of release strains (Foster et al., 1985; Hooper et al., 1987).

In a previous study, L. cuprina males carrying either of two related Y-linked translocations showed crossover frequencies several times higher than in chromosomally normal males (Foster et al., 1980a). Rössler $(1982 \mathrm{a}, \mathrm{b})$ reported male recombination in Ceratitis capitata, but his data suggested little difference between translocation and normal strains. The present study was aimed at discovering whether or not the apparently increased frequency of male recombination in Y-linked translocation strains of $L$. cuprina (Foster et al., 1980a) is caused by rearrangement of the $\mathrm{Y}$ or other chromosomes.

\section{Materials and methods}

\section{Mutations and strains}

The names and symbols of mutations mentioned in the present report are as follows: chromosome 3: white eyes (w), rusty body (ru), featherless aristae (ar), yellowish eyes (yw); chromosome 4: radial vein gaps (ra), short bristles (sh), singed vibrissae (sv), golden body (gl); chromosome 5: Fused veins (Fv), topaz eyes (to), stubby bristles (sby). Female linkage data for these mutations are contained in Foster et al. (1981) (also see Table 1). Complete descriptions, origins and other information are given by Maddern et al. (1986).

Table 1 Effects of translocations on crossing over on chromosome 3 in both sexes

\begin{tabular}{llllll}
\hline Genotype & $\begin{array}{l}\text { Autosomai } \\
\text { breakpoints }^{*}\end{array}$ & $\begin{array}{l}\text { Number of } \\
\text { matings } \dagger\end{array}$ & $\begin{array}{l}\text { Total } \\
\text { progeny }\end{array}$ & $\begin{array}{l}\text { Crossover } \\
r u-a r\end{array}$ & $\begin{array}{l}\text { Frequencies } \\
\text { ar-yw }\end{array}$ \\
\hline Females & & & & & \\
Nontrans, $F v$ & & 12 & 2,430 & 0.3305 & 0.0790 \\
Nontrans, $S h$ & & 12 & 1,994 & 0.3235 & $0.0552^{\mathrm{h}}$ \\
$T(3 ; 5) 411, F v$ & $33 \mathrm{~B} ; 74 \mathrm{~A}$ & 12 & 1,988 & 0.2862 & $0.0734^{\mathrm{b}}$ \\
$T(4 ; 5) 357, S h$ & $49 \mathrm{~A} ; 70 \mathrm{C} / 71 \mathrm{~A}$ & 12 & 2,079 & 0.3002 & $0.0991^{\mathrm{c}}$ \\
$T(3 ; 4) 230$ & $34 \mathrm{~A} ; 50 \mathrm{~A}$ & 12 & 2,324 & 0.2229 & $0.1011^{\mathrm{c}}$ \\
Males & & & & & \\
Nontrans, $F v$ & & 33 & 5,637 & 0.0016 & 0.0000 \\
Nontrans, $S h$ & & 28 & 5,160 & 0.0004 & 0.0000 \\
$T(3 ; 5) 411, F y$ & $33 \mathrm{~B} ; 74 \mathrm{~A}$ & 42 & 5,628 & $0.0121^{\mathrm{c}}$ & 0.0000 \\
$T(4 ; 5) 357, S h$ & $49 \mathrm{~A} ; 70 \mathrm{C} / 71 \mathrm{~A}$ & 33 & 3,205 & $0.0047^{\mathrm{b}}$ & 0.0000 \\
$T(3 ; 4) 230$ & $34 \mathrm{~A} ; 50 \mathrm{~A}$ & 38 & 5,291 & 0.0000 & 0.0000 \\
\hline
\end{tabular}

*Numerals and letters indicate standard polytene map regions (Foster et al, 1980b): chromosome 3, regions $21 \mathrm{~A}-40 \mathrm{C}$; chromosome 4 , regions $41 \mathrm{~A}-60 \mathrm{D}$; chromosome 5 , regions $61 \mathrm{~A}-80 \mathrm{D}$; chromosome 6 , regions $81 \mathrm{~A}-100 \mathrm{~B}$; Slash $(/)$ indicates breakpoint at junction of regions.

†All tests from single-pair matings. Homogeneity tests: $\mathrm{b}, \mathrm{c}=$ crossover frequency heterogeneous between pairs, $P<0.01,0.001$, respectively. 
The 15 translocations used in the present study were induced, over a period of several years, by irradiating mature sperm (5-day-old males) (2800 rads gamma rays from a ${ }^{60} \mathrm{Co}$ or a ${ }^{137} \mathrm{Cs}$ source) and using a number of crossing schemes to detect linkage of genetic markers on heterologous linkage groups (e.g. Foster \& Whitten, 1974\}. The translocations T(4;5)357,Sh (Foster, 1982), T(3;5)411,Fv, T(Y;5)529,Fv and $T(3 ; 5) 530, F v$ were induced in laboratory strains containing the dominant mutations $S h$ or $F v$, respectively. The others were induced in a succession of wild type strains derived from mass field collections near Canberra in the $1970 \mathrm{~s}(T(3 ; 4) 230$ and $T(3 ; 4) 257)$ and (all other translocations) near Canberra in 1983 and 1985, and on Flinders Island, Bass Strait in 1987. Thus genetic background was not uniform in these studies.

Translocation break points were determined using trichogen-cell polytene chromosomes prepared as shown by Bedo (1982) and classified according to the system of Foster et al. (1980b) in which the standard polytene chromosome map is divided into 100 regions (20 regions per autosome).

\section{Recombination assay procedure}

Recombination in females was assayed in single-pair matings. Control or translocation-bearing females heterozygous for multi-marker chromosomes were test-crossed to homozygous males and progeny were scored for recombination between the genetic markers.

Recombination in males was assessed using singlepair matings, individual males mated to several females, or mass-matings. Type of mating and genetic markers are identified in footnotes to Tables 1 and 2 . Control or translocation-bearing males heterozygous for multi-marker chromosomes were test-crossed to homozygous females and progeny were scored for recombination between the genetic markers.

Regardless of mating type, all progeny were obtained as broods reared from egg-masses (approximately $200-300$ eggs) laid by individual females.

\section{Culture conditions}

Larvae were reared on a choice of raw sheep liver or commercial pet food as rearing medium. All stages were incubated at an average temperature of $27 \pm 2^{\circ} \mathrm{C}$.

\section{Statistical analysis}

Homogeneity $G$-tests (Sokal \& Rohlf, 1969) were performed to test for homogeneity of crossover frequency.

\section{Results}

Data on the effects of three translocations on crossing over in chromosome- 3 in both sexes are summarized in Table 1. In females, crossover frequencies were generally similar in translocation and non-translocation crosses. With the possible exception of $T(3 ; 4) 230$, crossover frequencies for the $r u$ to $a r$ and ar to $y w$ regions were consistent with earlier data for these intervals (Foster et al., 1981).

In the reciprocal crosses, the results were very different (Table 1). First, crossover frequencies were considerably lower in males than in females. Secondly, in two of the translocation crosses male crossover frequencies were an order of magnitude higher than in the non-translocation crosses, while in the third translocation cross no crossovers were recovered. These results cannot be explained as localized effects of particular translocation breakpoints, since one of the rearrangements did not involve chromosome 3 , and the two which did involve this chromosome had similar chromosome-3 breakpoints (regions $33 \mathrm{~B}$ and $34 \mathrm{~A}$, respectively) (Table 1 ).

Male recombination was examined in a further series of crosses using various combinations of translocations and genetic markers. The data confirm that male crossover frequencies vary widely, whether or not translocations are present (Table 2). Frequencies of crossing over in non-translocation males occurred over a similar range (approximately $0.03-0.2$ per cent) on the three chromosomes tested. In translocation males the range of crossover frequencies was somewhat wider $(0-0.5$ per cent). However, no consistent effect of individual rearrangements or of rearrangement type was evident. For example, $T(Y ; 3) 414$ and $T(Y ; 3) 417$ generally gave lower crossover frequencies than nontranslocation males in experiment 2, but gave the opposite result in experiments 5 and 6 .

Analysis of heterogeneity revealed significant clustering (between-male heterogeneity) of crossovers in some crosses (Tables 1 and 2).

\section{Discussion}

The data in the present report are consistent with the finding of Foster et al. (1980a) that male crossing over in a $T(Y ; 5)$ and a $T(Y ; 3 ; 5)$ strain was several times higher than in a chromosomally normal strain. Contrary to previous speculation, however, the present data indicate that structural integrity of the Y chromosome has little or no influence on crossing over in male $L$. cuprina. Rearrangement of the $\mathrm{Y}$ chromosome appears to be neither sufficient nor necessary for high levels of male recombination. Moreover, male 
Table 2 The effects of translocation type and genetic background on male crossing over

\begin{tabular}{|c|c|c|c|c|c|c|c|c|c|c|}
\hline \multirow[b]{2}{*}{ Genotype } & \multirow[b]{2}{*}{$\begin{array}{l}\text { Autosomal } \\
\text { breakpoints* }\end{array}$} & \multicolumn{3}{|c|}{ Chromosome 3} & \multicolumn{3}{|c|}{ Chromosome 4} & \multicolumn{3}{|c|}{ Chromosome 5} \\
\hline & & $\begin{array}{l}\text { No. of } \\
\text { males } \dagger\end{array}$ & $\begin{array}{l}\text { Total } \\
\text { scored }\end{array}$ & $\begin{array}{l}\mathrm{C}-\mathrm{O} \\
\text { freq. }\end{array}$ & $\begin{array}{l}\text { No. of } \\
\text { males }\end{array}$ & $\begin{array}{l}\text { Total } \\
\text { scored }\end{array}$ & $\begin{array}{l}\mathrm{C}-\mathrm{O} \\
\text { freq. }\end{array}$ & $\begin{array}{l}\text { No. of } \\
\text { males }\end{array}$ & $\begin{array}{l}\text { Total } \\
\text { scored }\end{array}$ & $\begin{array}{l}\mathrm{C}-\mathrm{O} \\
\text { freq. }\end{array}$ \\
\hline \multicolumn{11}{|l|}{ Experiment 2} \\
\hline Nontrans & & $\mathbf{M}$ & 6,685 & 0.0015 & 4 & 1,950 & $0.0015^{\mathrm{T}}$ & & & \\
\hline$T(Y ; 3) 414$ & $32 \mathrm{~A}$ & $\mathbf{M}$ & 4,453 & 0.0002 & 4 & 1,070 & $0.004^{r}$ & & & \\
\hline$T(Y ; 3) 417$ & $33 \mathrm{C}$ & $\mathrm{M}$ & 363 & 0.000 & 4 & 1,939 & $0.0000^{r}$ & & & \\
\hline$T(3: 4) 257$ & $33 \mathrm{C} ; 50 \mathrm{~A}$ & $\mathbf{M}$ & 2,328 & 0.0000 & 4 & 1,313 & $0.0046^{r}$ & & & \\
\hline$T(3 ; 4) 485$ & $32 \mathrm{~A} ; 50 \mathrm{~A} / \mathrm{B}$ & $\mathbf{M}$ & 3,892 & 0.0000 & 4 & 888 & $0.001^{\mathrm{I}}$ & & & \\
\hline$T(Y ; 3 ; 4) 420$ & $\begin{array}{l}40 \mathrm{~A} ; 49 \mathrm{C} / 50 \mathrm{~A} \\
57 \mathrm{C} / \mathrm{D}\end{array}$ & $M$ & 2,337 & $0.0051^{\text {al }}$ & 4 & 263 & $0.004^{x}$ & & & \\
\hline \multicolumn{11}{|l|}{ Experiment 3} \\
\hline Nontrans & & 4 & 5,442 & $0.0017^{\mathrm{b}}$ & & & & & & \\
\hline$T(Y ; 3) 421$ & $28 \mathrm{C}$ & 4 & 2,099 & 0.0000 & & & & & & \\
\hline$T(Y ; 4 ; 6) 521$ & $43 \mathrm{~A} ; 50 \mathrm{~A} ; 84 \mathrm{~A}$ & 4 & 1,687 & 0.0012 & & & & & & \\
\hline$T(Y ; 4 ; 6), 522$ & $49 \mathrm{C} ; 56 \mathrm{~A} ; 91 \mathrm{~B}$ & 4 & 1,187 & 0.0008 & & & & & & \\
\hline \multicolumn{11}{|l|}{ Experiment 4} \\
\hline Nontrans, $F v$ & & 6 & 6,313 & $0.0022^{c}$ & & & & & & \\
\hline$T(Y ; 5) 529, F \nu$ & $76 \mathrm{~B}$ & 2 & 1,778 & 0.0011 & & & & & & \\
\hline$T(3 ; 5) 530, F v$ & $39 \mathrm{~B} ; 65 \mathrm{~B}$ & 6 & 3,642 & 0.0000 & & & & & & \\
\hline \multicolumn{11}{|l|}{ Experiment 5} \\
\hline Nontrans & & 3 & 1,233 & 0.001 & 6 & 3,147 & 0.0006 & 6 & 2,972 & 0.0003 \\
\hline$T(Y ; 3) 417$ & $33 \mathrm{C}$ & 3 & 375 & $0,000^{s}$ & 1 & 279 & 0.000 & 6 & 1,314 & 0,001 \\
\hline$T(Y ; 4) 497$ & $47 \mathrm{D}$ & 4 & 1,037 & $0.007^{\mathrm{c}}$ & 6 & 2,097 & $0.0019^{\mathrm{a}}$ & 4 & 837 & 0.000 \\
\hline$T(Y ; 5) 519$ & $73 \mathrm{C}$ & 5 & 805 & 0.000 & 2 & 1,241 & 0.001 & 6 & 1,426 & 0.0000 \\
\hline \multicolumn{11}{|l|}{ Experiment 6} \\
\hline Nontrans & & 12 & 7,040 & 0.0003 & 11 & 7,727 & $0.0017^{\circ}$ & 12 & 8,896 & $0.0018^{\mathrm{a}}$ \\
\hline$T(Y ; 3) 414$ & $32 \mathrm{~A}$ & 11 & 2,557 & 0.0012 & 11 & 6,606 & $0.0038^{a}$ & & & \\
\hline$T(X ; 3) 417$ & $33 \mathrm{C}$ & 10 & 2,696 & 0.0007 & 12 & 6,421 & $0.0048^{\mathrm{c}}$ & & & \\
\hline$T(Y, 4) 497$ & $47 \mathrm{D}$ & 9 & 2,812 & $0.0053^{c}$ & & & & 12 & 4,170 & $0.0046^{\circ}$ \\
\hline$T(\gamma ; 5) 519$ & $73 \mathrm{C}$ & & & & 11 & 5,270 & 0.0015 & & & \\
\hline
\end{tabular}

*See footnote to Table 1. $\$ Except as noted, number tested = number of individual males (see Methods); $M=$ = data from 4 males mass-mated to on average 7 females/male; $\mathrm{C}-\mathrm{O}$ freq. $=$ crossover frequency - except as noted, measured between $w-a r$ (chromosome 3), sv-gl (chromosome 4), to - sby (chromosome 5); $\mathrm{s}$ - crossovers between ar and sex $=0.005 ; \mathrm{r}-$ crossovers measured between $r a-g l$; homogeneity tests: $\mathrm{a}, \mathrm{b}, \mathrm{c}-$ crossover frequency heterogeneous between males, $P<0.05,0.01,0.001$, respectively; a1 - heterogeneous between individual-female broods from mass matings, $P<0.05$.

recombination frequencies do not appear to be consistently influenced by particular translocations. These findings are consistent with the data from $C$. capitata (Rössler, 1982a, b; Rössler \& Rosenthal, 1990).

In other higher dipteran species, the frequency of male recombination is also highly variable. In Drosophila ananassae, at least two autosomal loci affect crossing over in males, whose frequency can approach that in females (Hinton, 1970). Similarly high levels of male recombination have been reported in some lines of C. capitata (Rössler \& Rosenthal, 1990). Variability in male crossing over in $D$. melanogaster appears frequently to be associated with transposable mutator elements (Bregliano \& Kidwell, 1983), but the relationship between mutators and male crossing over in $D$. ananassae is problematic (Hinton, 1983). So far this type of element has not been identified in L. cuprina.

Clustering (heterogeneity) of crossing over has previously been used to identify whether male recombination is meiotic or premeiotic in origin (Hiraizumi, 1979; Hiraizumi et al., 1973; Henderson et al., 1978; Kidwell \& Kidwell, 1975, 1976; Woodruff \& Thompson, 1977). If recombination is premeiotic, occurring in spermatogonia, then clusters of spermatocytes will be produced which contain recombinant products. Transfer of these products during mating can 
result in clusters of recombinant progeny between males and also in different broods from a single male. However, similar clustering could also result if males are heterogeneous for factors affecting meiotic crossing over. The data from the current experiments do not permit a distinction between these hypotheses.

In the absence of positive evidence, we can only speculate that the variability in male recombination frequencies in $L$. cuprina may be genetic in origin. In $C$. capitata, Rössler \& Rosenthal (1990) reported that the highest levels of male recombination occurred in the presence of certain dominant mutations, but that the presence of these mutations did not always result in high levels of recombination. In the present study, the dominant markers used in some crosses had no such effect (Tables 1 and 2). The genetic background of a sexing strain may influence male recombination.

If genetic factors are responsible for the variability in male crossing over, it may be possible to select a strain whose genetic background is disposed toward lower recombination. However, it is probable that this would not be practicable for the mass-rearing of competitive insects for release. It is generally considered desirable to maintain as wide a genetic background as possible in mass-rearing colonies, to minimize the possibility of inbreeding depression in released insects (Whitten \& Foster, 1975).

To a considerable extent selecting translocations whose autosomal breakpoints are physically close to the critical sexing mutations may alleviate the male recombination problem in genetic sexing systems (Kerremans \& Busch-Petersen, 1990; Zapater, 1990), particularly those intended for use with sterilized male release. However, with FK systems using translocations involving three or more chromosomes, this could be incompatible with selection of translocations with a sterility level sufficiently high for population suppression yet not too sterile for practical mass-rearing (Foster et al., 1988). Strains with higher sterility require larger adult colonies and retention of higher proportions of the mass-reared product than strains with lower sterility, and are thus more difficult to rear economically. The FK system in $L$. cuprina uses a $T(Y ; 3 ; 5)$ translocation derived from a highly fertile $T(Y ; 5)$ progenitor (Foster, 1982), giving a strain with approximately 40 per cent egg-to-adult survival (Foster et al., 1985). The relatively high fertility of this 3-chromosome translocation results from the position of the breakpoint of the $T(Y ; 5)$ rearrangement with respect to male meiotic pairing sites on both the $\mathrm{Y}$ and the fifth chromosome (Bedo, 1987; Foster \& Maddern, 1985).

Including inversions in sexing systems to eliminate the products of crossing over may both provide a solution to the problem of male recombination
(Kerremans \& Busch-Petersen, 1990), and increase the available genetic death in FK systems (Foster, 1991). In species such as most mosquitos, which have high levels of male crossing over, the use of inversions to eliminate crossovers is routine in genetic sexing systems (Baker et al., 1979; Curtis et al., 1976; Kaiser et al., 1978).

\section{Acknowledgements}

Dr D. G. Bedo performed the cytological examinations of most of the rearrangements used in the present experiments. Julie Waterman, Bill James, Karen Paschalidis, Dave Charlton and Will Inveen assisted with rearing and scoring the crosses. This research was supported in part by funds from the Australian Meat and Livestock Research and Development Corporation and the Australian Wool Corporation.

\section{References}

BAKER, R, H., REISEN, W. K., SAKAI, R. K.. HAYES, C. G., ASLAMKHAN, M., SAIFUDDIN, U. T., MAHMOOD. F, PERVEEN, A. AND JAVED, $S$. 1979. A field assessment of mating competitiveness of male Culex tritaeniorhynchus carrying a complex chromosomal aberration. Ann. Entomol, Soc. Am., 72, 751-758.

BEDo, D. G. 1982. Differential sex chromosome replication and dosage compensation in polytene trichogen cells of Lucilia cuprina (Diptera: Calliphoridae). Chromosoma, 87, 21-32.

BEDO, D. G. 1987. Specific recognition and differential affinity of meiotic X-Y pairing sites in Lucilia cuprina (Diptera: Calliphoridae) males. Chromosoma, 95, 126-135.

BOYES, J. w. 1967. The cytology of muscoid flies. In: Wright, J. W. and Pal, R. (eds) Gentetics of Insect Vectors of Disease Elsevier, Amsterdam, pp. 371-384.

BREGLJANO, J. C. AND KIDWELL, M. G. 1983. Hybrid dysgenesis determinants. In: Shapiro, J. A. (ed.) Mobile Genetic Elements, Academic Press, New York, pp. 363-409.

BUSCH-PETERSEN, E, 1989. Male recombination in a genetic sexing strain of Ceratitis capitata (Diptera: Tephritidae) and its effect on stability. Ann. Entomol. Soc. Am., 82, 778-784.

CURTIS, C. F. AKIYAMA, J. AND DAVIDSON, G. 1976. A genetic sexing system in Anopheles gambiae species A. Mosq. News, 36, 492-498.

FOSTER, G. G. 1982. The use of bridging systems to increase genetic variability in compound chromosome strains for genetic control of Lucilia cuprina (Wiedemann). Theor. Appl. Genet., 63, 295-305.

FosTER, G. G. 1989. The sheep blowtly genetic control program in Australia. FAO/IAEA Insect and Pest Control Newsletter, No. 43, 23-26.

FOSTER, G. G. 1991. Chromosomal inversions and genetic control revisited: The use of inversions in sexing systems for higher Diptera. Theor. Appl. Genet., 81, 619-623.

FOSTER, G. G. AND MADDERN, R. H. 1985. Segregation and pairing of compound fifth-chromosomes in Lucilia cuprina 
males. Genet. Res. Camb. 46, 149-168.

FOSTER, G. G. AND WHITTEN, M. I. 1974. The development of genetic methods of controlling the Australian sheep blowfly, Lucilia cuprina. In: Pal, R. and Whitten, M. J. (eds) The Use of Genetics in insect Control, Elsevier/North Holland, Amsterdam, pp. 19-43.

FOSTER, G. G., WHITTEN, M. J., VOGT, w. G., WOODBURN, T. L. AND ARNoLD. J. T. 1978. Larval release method for genetic control of the Australian sheep blowfly Lucilia cuprinta Wiedemann (Diptera: Calliphoridae). Bull. Ent. Res., 68, $75-83$.

FOSTER, G. G., MADDERN, R. H. AND MILls, A. T. 1980a, Genetic instability in mass-rearing colonies of a sex-linked translocation strain of Lucilia cuprina Wiedemann (Diptera: Calliphoridae) during a field trial of genetic control. Theor. Appl. Genet., 58, 169-175.

FOSTER, G. G., WHITTEN, M. J., KONOVALOV, C., BEDO, D. G., MADDERN, R. H. AND BOON, D. J. 1980 b. Cytogenetic studies of Lucilia ctupina dorsalis R-D. (Diptera: Calliphoridae): Polytene chromosome maps of the autosomes and cytogenetic localization of visible genetic markers. Chromosoma, $\mathbf{8 1}$, $151-168$.

FOSTER, G. G., WHITTEN, M. J., KONOVALOV, C., ARNOLD, J. T. A. AND MAFF, G. 1981. Autosomal genetic maps of the Australian sheep blowfly, Lucilia cuprina dorsalis R.-D. (Diptera: Calliphoridae), and possible correlations with the linkage groups of Musca domestica (L.) and Drosophila melanogaster (Mg.). Genet. Res. Camb., 37, 55-69.

FOSTER, G. G., vOGT, w. G. AND wOODBURN, T. L. 1985. Genetic analysis of field trials of sex-linked translocation strains for genetic control of the Australian sheep blowtly Lucilia cuprina Wiedemann. Aust. J. Biol. Sci, 38, 275-293.

FOSTER, G. G., VOGT, W. G., WOODBURN, T. L. AND SMITH, P. H. 1988. Computer simulation of genetic control. Comparison of sterile males and field-female killing systems. Theor. Appl. Genet., 76, 870-879.

HENDERSON, S. A., WOODRUFF, R. C. AND THOMPSON, J. N. 1978. Spontaneous chromosome breakage at male meiosis associated with male recombination in Drosophila melanogaster. Genetics, 88, 93-107.

HINTON, C. W. 1970. Identification of two loci controlling crossing over in males of Drosophila ananassae. Genetics, $66,663-676$.

HINTON, C. w. 1983. Relations between factors controlling crossing over and mutability in males of Drosophila ananassae. Genetics, 104, 95-112.

HIRAJZUMI, Y. 1979. A new method to distinguish between meiotic and premeiotic recombinational events in Drosophila melanogaster, Genetics, 92, 543-554.

HIRAIZUMI, Y., SLATKO, B., LANGLEY, C. AND NILL, A. 1973. Recombination in Drosophila melanogaster male. Genetics, 73, 439-444.

HOOPER, G. H. S., ROBINSON, A. S. AND MARCHAND, R. P. 1987. Behaviour of a genetic sexing strain of Mediterranean fruit fly, Ceratitis capitata, during large scale rearing. In: Economopoulos, A. P. (ed.) Fruit Flies: Proceedings of the Second International Symposium, Elsevier, Amsterdam, pp. 349-362.

KAISER, P. E, SEAWRIGHT, J. A, DAME, D. A. AND JOSLYN, D. J. 1978.
Development of a genetic sexing system for Anopheles albimanus. J. Econ. Entomol., 71, 766-771.

KERREMANS, P. AND BUSCH-PETERSEN, E. 1990. Polytene chromosome analysis in relation to genetic sex separation in the Mediterranean fruit fly, Ceratitis capitata (Wied.). In: Genetic Sexing of the Mediterranean Fruit Fly, International Atomic Energy Agency, Vienna, pp. 61-68.

KIDWELL, M. G. AND KIDWELL, J. F. 1975. Spontaneous male recombination and mutation in isogenic-derived chromosomes of Drosophila melanogaster: J. Hered, 66 , $367-375$.

KIDWELL., M. G. AND KIDWELL, J. F 1976. Selection for male recombination in Drosophila melanogaster, Genetics, 84, 333-351.

MADDERN, R. H., FOSTER, G. G., WHTTEEN, M. J., CLARKE, G. M., KONOVALOV, C. A., ARNOLD, J. T. A. AND MAFFI, G. 1986. The genetic mutations of Lucilia cuprina dorsalis R.-D. (Diptera: Calliphoridae). Commonwealth Scientific and Industrial Research Organization, Austratia. Division of Entomology Report No. 37.

McDONALD, 1. C. 1971. A male producing strain of the housefly. Science, 172, 489 .

MILANI, R. 1975. The house fly, Musca domestica. In: King, R. C. (ed.) Handbook of Genetics. vol. 3, Plenum Press, New York, pp. 337-399.

ROBINSON, A. S. AND VAN HEEMERT, C. 1982. Ceratitis capitataa suitable case for genetic sexing. Genetica, 58, 229-237.

RöSsLER, Y. 1982a. Genetic recombination in males of the Mediterranean fruit fly, and its relation to automated sexing methods. Ann. Entomol. Soc. Am., 75, 28-31.

ROSSLER, Y. $1982 \mathrm{~b}$, Recombination in males and females of the Mediterranean fruit fly, (Diptera: Tephritidae) with and without chromosomal aberrations, Ann. Entomol. Soc. Am., 75, 619-622.

ROSSLER, Y. AND ROSENTHAL, H. 1990. Genetics of the Mediterranean fruit fly, Ceratitis capitata (Wied.). In: Genetic Sexing of the Mediterratean Fruit Fly, International Atomic Energy Agency, Vienna, pp. 69-83.

SAUL, S. H. 1984. Genetic sexing in the Mediterranean fruit fly, Ceratiris capitata (Wiedemann) (Diptera: Tephritidae): conditional lethal translocations that preferentially eliminate females. Ann. Entomol. Soc. Am., 77, 280-283.

SOKAL, R. R. AND ROHLF, F. J. 1969. Biometry. W. H. Freeman \& Co., San Francisco.

TAZImA, y. 1964. The Genetics of the Silkworm. Logos, London,

ULLERICH, F.H. 1963. Geschlechtschromosomen und Geschlechstbestimmung bei einigen Calliphorinen (Calliphoridae, Diptera), Chromosoma, 14, 45-110.

WAGONER, D. E., McDonAld, I. C. AND CHILDRESS, D. 1974. The present status of genetic control mechanisms in the housefly, Musca domestica L. In: Pal, R. and Whitten, M. J. (eds) The Use of Genetics in Insect Control, Elsevier/North Holland, Amsterdam, pp. 183-197.

WHITTEN, M. J. 1969. Automated sexing of pupae and its usefulness in control by sterile insects. J. Econ. Entomol., 62, 272-273.

WHITTEN, M. J. 1979. The use of genetically selected strains for pest replacement or suppression. In: Hoy, M. A. and 
McKelvey, J. J. Jr (eds) Genetics in Relation to Insect Management, The Rockefeller Foundation, New York, pp. 31-40.

WHITIEN, M. J. AND FOSTER, G. G. 1975. Genetical methods of pest control. Ann. Rev. Entomol., 20, 461-476.

WHITTEN, M. I., FOSTER, G. G., VOGT, W. G., KITCHING, R. L, WOODBURN, T. L. AND KONOVALOV, C. 1977. Current status of genetic control of the Australian sheep blowfly, Lucilia cuprina Wiedemann (Diptera: Calliphoridae). Proc. $\mathrm{XV}$
Int. Cong. Entomol., Washington, D.C. 1976, pp. $129-139$.

WOODRUFF, R. C. AND THOMPSON, J. N. 1977. An analysis of spontaneous recombination in Drosophila melanogaster males. Isolation and characterisation of male recombination lines. Heredity, 38, 291-307.

ZAPATER, M. 1990. Two new pupal sexing strains in the Mediterranean fruit fly, Ceratitis capitata (Wied.). In: Genetic Sexing of the Mediterranean Fruit Fly, International Atomic Energy Agency, Vienna, pp, 107-113. 